Kenya Murayama, Thomas Taro Lennerfors, Kiyoshi Murata:

\title{
Winny and the Pirate Bay: A comparative analysis of P2P software usage in Japan and Sweden from a socio-cultural perspective
}

\begin{abstract}
:
In this paper, we examine the ethico-legal issue of P2P file sharing and copyright infringement in two different countries - Japan and Sweden - to explore the differences in attitude and behaviour towards file sharing from a socio-cultural perspective. We adopt a comparative case study approach focusing on one Japanese case, the Winny case, and a Swedish case, the Pirate Bay case. Whereas similarities in attitudes and behaviour towards file sharing using P2P software between the two countries are found in this study, the Swedish debate on file sharing has been coloured by an ideological and political dimension, which is absent in the Japanese context. This might indicate that Swedes have been more interested in issues of right and wrong, and the creation of political subject of piracy, while the Japanese are more interested in their own individual well being.
\end{abstract}

\section{Agenda:}

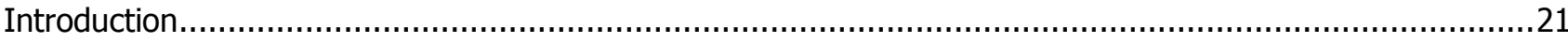

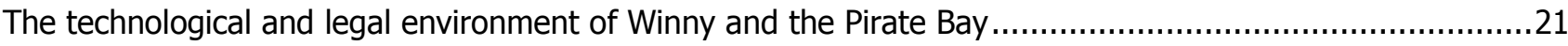

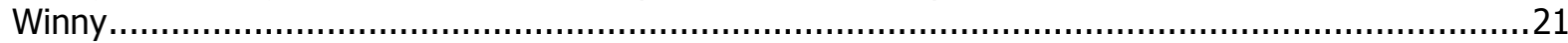

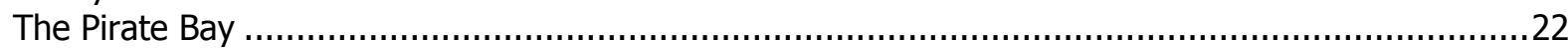

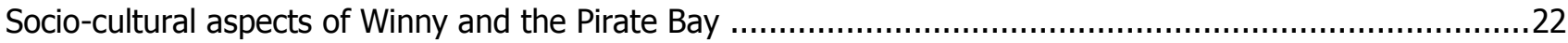

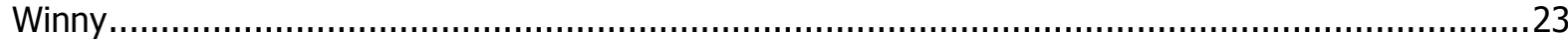

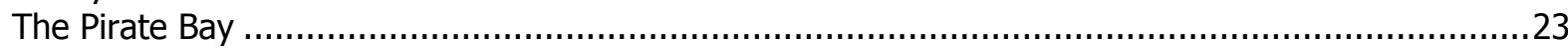

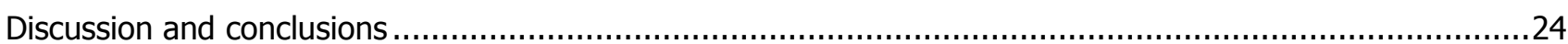

\section{Authors:}

Kenya Murayama:

- Graduate School of Commerce, Meiji University, 1-1 Kanda Surugadai, Chiyoda, Tokyo 101-8301, Japan

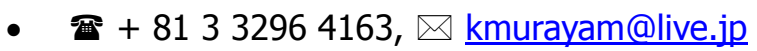

Dr. Thomas Taro Lennerfors:

- Centre for Business Information Ethics, School of Commerce, Meiji University, 1-1 Kanda Surugadai, Chiyoda, Tokyo 101-8301, Japan

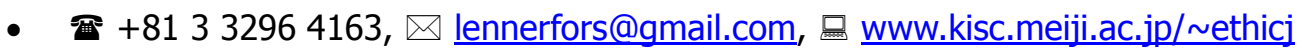

Prof. Kiyoshi Murata:

- Centre for Business Information Ethics, School of Commerce, Meiji University, 1-1 Kanda Surugadai, Chiyoda, Tokyo 101-8301, Japan

- $\widetilde{\widetilde{m}}+8133296$ 2165, $\square$ kmurata@kisc.meiji.ac.jp, 昌 www.kisc.meiji.ac.jp/ ethicj

- Relevant publications: See http://rwdb2.mind.meiji.ac.jp/Profiles/8/0000746/prof e.html 


\section{Introduction}

In this paper, we address how two particular cultures respond to problems arising from the use of information and information technology. More specifically, we address the ethico-legal issue of P2P file sharing and copyright infringement in two different countries - Japan and Sweden. Even though these countries are similar in their being technologically advanced and comprising an Internet savvy population, in this paper we would like to explore the differences in attitude and behaviour towards file sharing between Japan and Sweden especially from a socio-cultural perspective. Such an investigation can indeed be made by quantitative analyses of the use of and attitudes towards P2P file sharing, but we have aimed for adopting a comparative case study approach focusing on one case in Japan, the Winny case, and the other case in Sweden, the Pirate Bay (TPB) case. An analysis of these two cases, which both developed into court cases, will constitute the core of this paper. First, we will briefly describe the cases and particularly focus on the differences in the technological and legal framework between these two cases (or countries). Second, we will deepen our analysis of the cases from a sociocultural perspective digging deeper into issues of ethics rather than law. Third, in a comparative discussion, we will pin down some similarities and differences in the use of and attitudes towards P2P file sharing between the two countries before we move on to a final discussion about the possible implications of this study.

\section{The technological and legal environment of Winny and the Pirate Bay}

Today, many cases of copyright infringement occur due to the widespread use of P2P software all over the world. The very use of P2P software does not imply copyright infringement, since there are many ways of legitimately using file sharing protocols. However, according to a survey of the Association of Copyright for Computer Software (ACCS 2009), $98.0 \%$ of file sharing in P2P networks concern files protected by copyright.

When P2P file sharing started, it had already been illegal to upload files with copyright in Japan, but to download copyrighted files was not necessarily illegal. However, since January 2010, it has become illegal to download music or video files with copyright. In Sweden as well, only uploading copyrighted materials used to be illegal. However, since the amendment of the file sharing law (Fildelningslagen) on July 1, 2005, downloading copyrighted files has also been illegal. The Swedish legal framework was further amended in April 2009, when the controversial IPRED law (based on the EU directive IPRED), which allows copyright holders to force Internet service providers to reveal details of users' file sharing activities, came into effect.

Having very briefly described the legal framework in the two countries, we now turn to the cases.

\section{Winny}

The P2P software called Winny was developed by Isamu Kaneko in 2002 and has been used by many Japanese to share files. Kaneko had assumed an assistant professor position at a renowned university, and excelled in programming technology. His first purpose was to develop a perfectly encrypted file sharing system; according to his remark presented on the 2-Channel, the biggest Japanese BBS site, he wanted to develop a system with high anonymity allowing users to share copyrighted files without fear of being detected and prosecuted. He developed the file sharing system based on the Freenet system (http://freenetproject.org) with a user-friendly interface like WinMX, another popular P2P file sharing software. Win"ny" was named after WinMX as a successor to it. The Winny system does not need a central server, but peers are connected directly with other peers and each peer can maintain high anonymity, leading to its high popularity among young computer users.

As Winny spread in Japan, it became regarded as a problematic system due to the promotion of illegal online behaviour such as copyright infringement and distribution of obscene materials and child pornography. In November 2003 two Winny users were arrested for copyright infringement and in May 2004 the developer was arrested for assisting copyright infringement by High-tech Crime Division, Kyoto Prefectural Police Department. In addition, since March 2004, many cases of data leakage have been reported. Data leakage is caused by worms named "Antinny" spreading over the Winny network, that make files stored in hard disks of personal computers sharable via Winny (Orito \& Murata 2008). Nevertheless, the number of Winny users has not decreased. The statistics of ACCS (2004; 2005) 
show that the number of Winny users was 480 thousand in April 2004, just before the developer was arrested, and 634 thousand in January 2005. Moreover, following Winny, new P2P file sharing systems with high anonymity such as "Share" and "Perfect Dark" were developed and have been widely used.

\section{The Pirate Bay}

The website TPB was started in November 2003 and has since then grown to become one of the world's biggest BitTorrent trackers (Traffic rank 100 according to alexa.com, and rank 20 in Sweden and Norway), allowing users to easily access BitTorrent files. BitTorrent divides the shared files into small fragments, which is suitable for distributing larger files such as movies. TPB does not store any copyrighted files, but only addresses to these files. Therefore, it serves as the infrastructure for file sharing. An important difference from the Winny software is that user anonymity cannot be guaranteed.

TPB does not control the linked content, which became clear in September 2008 when sensitive material from a Swedish murder case leaked out on TPB and the operators of TPB refused to delete this information. They also have not agreed to delete copyrighted material. The founders of TPB believe that they just provide the platform for file sharing and that file sharing per se is not wrong. TPB was in the beginning praised for its innovative platform for file sharing and seen as a leader in Internet technology. At the same time, however, copyright was a constant issue that was discussed whenever the name TPB was mentioned.

On May 31, 2006, the Swedish police raided PRQ where TPB servers, which allegedly contained proof of copyright infringement, were hosted. Soon after the servers were confiscated, TPB started operations from the Netherlands, and just two weeks after the confiscation TPB resumed its service from Sweden. During this tense period, TPB changed its logo from its regular pirate ship, to a pirate ship firing cannon balls at the logo of Hollywood, expressing its discontent with the confiscation, which according to some sources could have been triggered by the American film industry.

Based on the material from the confiscated servers, on January 31, 2008 prosecutor Håkan Roswall brought an indictment on four people related to TPB for violation of copyright, assistance for violation of copyright, and preparation for violation of copyright.
The case is about 20 pieces of music, nine films and four computer games. SEK 1.2 million in indemnification is demanded by the State. The record companies demanded SEK 15 million in compensation and American film companies demanded SEK 93 million.

On February 16, 2009, the Pirate Bay trial started at the Stockholm District Court lasting for about two weeks. On April 17, 2009, the four people were found guilty for assisting in making copyrighted content available. Each defendant was sentenced to one year in prison. They were ordered to pay SEK 30 million. All the defendants have appealed the verdict. Representatives of the film industry also appealed seeking higher compensation. After the verdict, the members of the Pirate Party drastically increased, possibly showing discontent with the verdict. On May 12, 2010, the Supreme Court decided that there was no case of challenge/partiality. The defendants are considering appealing to the Court of Justice of the European Union (EU). Therefore, it will probably take six or seven years before a final verdict is reached.

\section{Socio-cultural aspects of Winny and the Pirate Bay}

The P2P technology community has been characterised by their respect for civil liberty on the Net, typically observed in hacker ethic (Himanen, 2001), the development of web-based censorship- and tampering-resistant publishing systems such as Publius (Waldman, Cranor \& Rubin, 2001) and the free software movement, the GNU project (http://www.gnu.org/gnu/thegnuproject.html), led by Richard Stallman.

In this part, we will argue that TPB case has this aspect. On the contrary, however, we will argue that one cannot find any relationship between the Winny case and the culture of the P2P technology community, since Winny users use P2P as a means of acquiring files with no deeper ethical motivation. This reflects the culture of Japan where technology tends to be considered unrelated to nontechnological factors including society. In this regard, the Winny case shows a striking contrast to the TPB case. 


\section{Winny}

As described above, despite the arrests of the developer and users of Winny, the majority of P2P file sharing software users in Japan have not stopped using Winny; directly after some users were arrested, the general use of Winny decreased, but just after a few weeks, usage of this P2P software was back at the previous level. As a result, copyright infringement occurs every day.

Personal, as well as public, information leakage brought about by Antinny, which were allegedly developed to punish persons for using Winny for illegal activities such as digital theft, has become a serious social problem. Personal information leaked has been used for the purpose of involuntary personal identity disclosure (Sarashi in Japanese). The Information-technology Promotion Agency of Japan (IPA), which has led information security policies in Japan, urged users not to use P2P software. However, an employee of IPA used Winny and his personal computer was infected by Antinny leading to his personal information being leaked. Although this was a shocking case, it was not covered by the newspapers, but only discussed on Internet news sites in Japan (IT Media News, 2009). The lack of coverage in newspapers might contribute to the low awareness of such risk among the Japanese public at large. What one can learn from the Winny case is that usage of P2P software has not decreased even though the developer and even some users were arrested. Why?

One aspect is that, in a collectivist society which Japan is considered to be, the Japanese are prone to go along with the crowds; a sense of agreeableness is considered more valuable than confirming one's identity in Japanese society. The proverb "the nail that sticks up gets hammered down" describes the Japanese culture well. Takeshi Kitano, film director and comedian, came up with the similar saying "If everyone crosses against the red light, then there's nothing to be afraid of" in the mid-80s, and many people retain sympathy for this idea; it is acceptable for them to commit a misdemeanor when everyone surrounding them does. Therefore, P2P software users in Japan tend to consider it is permissible to use P2P software because many others use it.

A central part of this is that Japanese people are relatively unaware of their rights (Kawashima, 1967), partly because many of them were not products of citizens' struggle to achieve them, but were just imported from abroad. This unawareness has been a stumbling block in individuals' participation in and commitment to society. Ordinary Japanese young Net users know there is something called copyright, but do not care about what the right is and why it should be protected. They are indifferent to the reality that copyright has a dimension of protecting vested interests of middlemen, not artists or creators, in the music and film industries. In fact, few Internet forums (e.g. 2-Channel, P2P interpretive site, etc) have discussed copyright issues. Rather, the interest of P2P file sharing software users is in whether they can enjoy sharing copyrighted files using the software without fear for being detected and/or arrested. For example, there is a thread titled "Why BitTorrent usage does not lead to being arrested" on the 2-Channel. The problem of copyright infringement has never been discussed in this thread. Thus it appears that illegal file sharing does not have any political motivation.

On the other hand, the developer of Winny told that the existing business model of the Japanese digital contents industry was already ineffective and a creative destruction of the industry based on new technology including his P2P software system was necessary. However, most Winny users are not interested in a business model of the digital contents industry; all that they want is to enjoy exchanging files of movie, music, game and other applications online. In fact, a WinMX user arrested for copyright infringement told in the interview that he merely wanted to obtain files using P2P file sharing software to expand his digital file collection. The benefit of free or costless sharing of digital contents files was emphasised. Therefore, when the developer of Winny was arrested, Winny users' concern was just about subsequent availability of Winny services and this led to the development of other P2P software such as "Share."

\section{The Pirate Bay}

The Pirate Bay case on the contrary has always concerned the issue of copyright, since its inception in 2003. Similarly to the Winny case, a lot of discussions about TPB have taken place on Internet forums, but TPB has also been discussed in Swedish newspapers. As can be understood from the name, TPB has always been a provocative, and some would say ideological player. In Sweden and abroad, TPB has become one of the focal points for the discussion about file sharing. TPB has some points in common with the Pirate Bureau, a Swedish thinktank on file sharing and freedom of speech. This

Kenya Murayama, Thomas Taro Lennerfors, Kiyoshi Murata: 
organization was formed in 2001, probably as a reaction to the Anti-Pirate Bureau (Antipiratbyrån), representing the interests of the record and film industry. TPB was founded by the Pirate Bureau, but is now run independently of it, even though some people are active in both organisations. Further related to this pirate movement is the Pirate Party, a party striving to reform laws regarding copyright and patents. The party also fights for increased right to privacy and the transparency of state administration (www.piratpartiet.se). The Pirate Party won $0.63 \%$ in parliamentary elections in 2006, and in the European Parliament election in 2009, the Pirate Party polled at $7.1 \%$ which gave it one seat in the European Parliament occupied by Christian Engström.

Moreover, TPB case is thus not only about file sharing as such, but also about a struggle for free file sharing without intrusion from "big business" such as the American music industry and Hollywood. In other words, TPB is an agent of civil disobedience for freedom of sharing digital files. In many newspaper articles, Sweden's independence towards bigger political entities such as the U.S. (claiming indemnification for copyright infringement) and the EU (for the IPRED law) is discussed. To sum up, due to its strong (and provocative) brand, TPB is a central player in the discussions about file sharing and copyright in the Swedish context. One can thus say that TPB has played the role of a copyleft activist against the establishment of copyright.

However, Jonas Andersson, a Swedish researcher on file sharing argues that "entities such as The Pirate Bay are controversial, despite the fact that the existing technical infrastructure of the Internet favors this type of data exchange" (Andersson 2009, 30 ). Andersson argues that the movement is politicised because of the brand and the frequent media appearances, even though many of the users just see file sharing as an everyday means of consuming culture.

The results from the parliamentary elections in Sweden in 2010 will give some insight into how much support the Pirate Party has today, and whether we can talk about a politicised file-sharing movement in Sweden or not.

\section{Discussion and conclusions}

Our conclusions are that Japanese young P2P users have low awareness of copyright protection. A lot of
Japanese P2P users stop use for a while when an incident happens, but after a while, restart the use of P2P. Discussions on web forums concern the risk of being caught, which indicates a somewhat individualistic approach to file sharing. In Sweden, illegal file sharing was also back at previous levels after the IPRED law came into effect (Zeropaid 2009), which indicates a similarity between Swedish and Japanese users. However, the Swedish debate on file sharing has been coloured by an ideological and political dimension, which is absent in the Japanese context. This might indicate that Swedes have been more interested in issues of right and wrong, and the creation of political subject of piracy, while the Japanese are more interested in their own individual well being (trying to avoid being arrested), reversing the well-worn dichotomy of individualism (Sweden) / collectivism (Japan).

\section{Acknowledgements}

This study is part of an open research centre project for private universities entitled "Quality-oriented Human Resource Development and Smart Business Collaboration: Quality Management Science," with a matching fund subsidy provided by the Japanese Ministry of Education, Culture, Sports, Science, and Technology (MEXT) for the period 2007-2012. The study was also supported by MEXT Grant-in-Aid for Scientific Research (C) 22530378.

\section{References}

2 channel, "Why BitTorrent usage does not lead to being arrested?" Available online at http://hideyoshi.2ch.net/test/read.cgi/download L1266710761/ (accessed on 14th April 2010). In Japanese.

ACCS (2004): Survey on File Sharing Software Usage in 2004, Association of Copyright for Computer Software. Available online at http://www2.accsjp.or.jp/activities/pdf/p2psurve y2004.pdf (accessed on 28th July 2010). In Japanese.

ACCS (2005): Survey on File Sharing Software Usage in 2005, Association of Copyright for Computer Software. Available online at http://www2.accsjp.or.jp/activities/pdf/p2psurve y2005.pdf (accessed on 28th July 2010). In Japanese.

ACCS (2009): Survey on File Sharing Software Usage in 2009, Association of Copyright for Computer Software. Available online at http://www2.accsjp.or.jp/activities/pdf/p2psurve

Kenya Murayama, Thomas Taro Lennerfors, Kiyoshi Murata: Winny and the Pirate Bay: A comparative analysis of P2P software usage in Japan and Sweden from a socio-cultural perspective 
y2009b.pdf (accessed on 5th March 2010). In Japanese.

Andersson, Jonas (2009): For the Good of the Net: The Pirate Bay as a Strategic Sovereign, Culture Machine, Vol. 10: 64-108.

Download regulation interpretive site. Available online at http://www39.atwiki.jp/dl-ihou/ (accessed on 14th April 2010). In Japanese.

Himanen, Pekka (2001): The hacker ethic, and the spirit of the information age, New York, Random House.

IT Media News (2009): IPA took disciplinary action against their employee: information leakage due to Winny and Share. Available online at http://www. itmedia.co.jp/news/articles/0901/19 Inews085.html (accessed on 14th April 2010). In Japanese.

Kawashima, Takeyoshi (1967): Japanese Sense of Law. Tokyo, Iwanami Shoten. In Japanese.

Net Agent, Transition analyses of number of Winny nodes, Available online at http://forensic.netagent.co.jp/winny node.htm/ (accessed on 14th April 2010). In Japanese.
Orito, Yohko \& Murata, Kiyoshi (2008): Sociocultural analysis of personal information leakage in Japan, Journal of Information, Communication \& Ethics in Society, 6 (2): 161-171.

P2P interpretive site. Available online at http://magic3.net/winny.htm/ (accessed on 14th April 2010). In Japanese.

Waldman, Marc, Cranor, Lorrie Faith \& Rubin, Avi (2001): "Publius," in Oram, Adam ed.: Peer-topeer: harnessing the benefits of a disruptive technology, Sebastopol, CA, O'Reilly, 145-158.

Zeropaid (2009): Post IPRED, File-Sharing in Sweden is "Healthier than Ever." Available online at http://www.zeropaid.com/news/87342/postipred-file-sharing-in-sweden-is-healthier-thanever/ (accessed on 14th April 2010). 